\title{
A dimensão interdisciplinar na construção da Educação Ambiental: Uma proposta de sequência didática
}

\author{
The interdisciplinary dimension in the construction of Environmental Education: A proposal for \\ teaching sequence \\ La dimensión interdisciplinaria en la construcción de la Educación Ambiental: Una propuesta de
} secuencia didáctico

\section{Resumo}

A Educação Ambiental tem como objetivo a sensibilização e conscientização ambiental. Este cenário socioeducacional, portanto, motiva à investigação de implicações decorrentes da relação entre as identidades espaciais locais e o processo de alfabetização científica sobre o Ensino de Ciências, que objetiva a construção do pensamento científico, tendo como princípio fundante a construção de habilidades e conceitos preliminares em período escolar dos Anos Iniciais do Ensino Fundamental. Dessa forma, o objetivo neste estudo é propor uma sequência didática para desenvolver a Educação Ambiental de maneira interdisciplinar. A presente pesquisa, trata de uma pesquisa-ação, com abordagem qualitativa, tendo como público alvo professores e estudantes do sexto e sétimo ano de uma Escola Pública, do município de Santa Maria, Rio Grande do Sul, Brasil. A proposta resultou em um importante recurso para os processos de ensino e de aprendizagem, pois visou articular os saberes curriculares da escola com a Educação Ambiental de uma maneira diferenciada e instigante e tem potencial para ser aplicada em diferentes contextos escolares, tendo sempre em mente que as disciplinas dialogam constantemente com as outras áreas do conhecimento, e, por meio de ações concretas, o aprendizado do aluno é favorecido.

Palavras-chave: Ensino de Ciências; Sequência didática; Educação Ambiental.

\begin{abstract}
Environmental Education aims to raise environmental awareness and awareness. This socio-educational scenario, therefore, motivates the investigation of implications arising from the relationship between local spatial identities and the process of scientific literacy on Science Teaching, which aims at the construction of scientific thinking, having as its founding principle the construction of preliminary skills and concepts. In the school period of the Early Years of Elementary School. Thus, the objective in this study is to propose a didactic sequence to develop Environmental Education in an interdisciplinary way. This research deals with action research, with a qualitative approach, with the target audience of teachers and students from the sixth and seventh year of a Public School, in the municipality of Santa Maria, Rio Grande do Sul, Brazil. The proposal resulted in an important resource for the teaching and learning
\end{abstract}


processes, as it aimed to articulate the school's curricular knowledge with Environmental Education in a different and exciting way and has the potential to be applied in different school contexts, always keeping in mind that the disciplines are in constant dialogue with other areas of knowledge, and, through concrete actions, student learning is favored.

Keywords: Science teaching; Following teaching; Environmental Education.

\section{Resumen}

La Educación Ambiental tiene como objetivo aumentar la conciencia y la conciencia ambiental. Este escenario socioeducativo, por tanto, motiva la investigación de las implicaciones que surgen de la relación entre las identidades espaciales locales y el proceso de alfabetización científica en la Enseñanza de las Ciencias, que apunta a la construcción del pensamiento científico, teniendo como principio fundacional la construcción de competencias y habilidades. Conceptos preliminares durante el período escolar de los primeros años de la escuela primaria. Así, el objetivo de este estudio es proponer una secuencia didáctica para desarrollar la Educación Ambiental de manera interdisciplinar. Esta investigación aborda la investigación acción, con un enfoque cualitativo, con el público objetivo de docentes y estudiantes de sexto y séptimo año de una Escuela Pública, en el municipio de Santa María, Rio Grande do Sul, Brasil. La propuesta resultó en un recurso importante para los procesos de enseñanza y aprendizaje, ya que tuvo como objetivo articular los conocimientos curriculares de la escuela con la Educación Ambiental de una manera diferente y apasionante y tiene potencial para ser aplicada en diferentes contextos escolares, siempre teniendo en cuenta que la Las disciplinas están en constante diálogo con otras áreas del conocimiento y, a través de acciones concretas, se favorece el aprendizaje de los estudiantes.

Palabras clave: Enseñanza de las ciencias; Siguiendo la enseñanza; Educación Ambiental.

\section{Introdução}

O Ensino de Ciências, como recorte do currículo escolar, compreende forte contribuição à formação da Educação Ambiental, uma vez que busca a construção do conhecimento científico, o qual é impulsionado pelo pensamento indagador, questionador, reflexivo.

Esse pensamento sobre feições reflexivas, imaginativas e instigadoras compreende o pensamento científico. Reflexão, imaginação e indagação se concebem pela percepção humana diante da realidade vivenciada. A realidade próxima compreende os espaços locais, constituídos por identidades socioculturais, das quais emergem sentimento de pertencimento. Pertencimento que incita ao conhecimento, à intervenção. Uma realidade adjetivada por desafios e questões. A mente humana, portanto, passa a se mobilizar para a superação. Nesse caminho então, são agilizadas habilidades, conhecimentos e competências, as quais dão forma ao pensamento científico. (Vestena, Ortiz, Santos, 2018, p. 17-18)

O Ensino de Ciências, em colaboração com demais áreas do currículo escolar, sejam elas Linguagem, Matemática e Humanas, tem como objeto de estudo processos de formação, funcionalidade e dinâmica da sociedade e natureza, em suas relações, conflitos e contradições. Todas essas áreas se agregam na constituição da Educação Ambiental, que tem como objetivo a formação da consciência ambiental.

Esse cenário socioeducacional, portanto, motiva à investigação de implicações decorrentes da relação entre as identidades espaciais locais e o processo de alfabetização científica sobre o Ensino de Ciências, que objetiva a construção do pensamento científico, tendo como princípio fundante a construção de habilidades e conceitos preliminares, em período escolar dos Anos Iniciais do Ensino Fundamental.

Os recortes espaciais locais são os lugares. A afirmação de identidades humanas e naturais que se arranjam sobre o lugar, ao longo de um tempo presente e passado, reafirmam sentimentos de pertencimento e identidade aos integrantes do lugar. Essa forma de ser, viver, sentir, construir, pertencer ao lugar, legitima sua identidade. Assim, como afirma Yázigi (2001, p. 49), “considero que o lugar está para o espaço, assim como a periodização está para o tempo”. O lugar tem História; a História marca o lugar. O lugar representa testemunho de concretizações acontecidas ao longo do e no tempo histórico. A sensibilização e conscientização ambiental passa, fundamentalmente, pelo conhecimento e pela valorização de espaços vividos. A Educação Ambiental tem na consciência ambiental seu objetivo maior, considerada como a retomada crítico-reflexiva em 
que o ser humano irá imbuir-se desse espírito, agindo sobre a realidade socioambiental em que se insere para modificá-la e/ou conservá-la. Esse espaço próximo ocupado, é o lugar. O lugar representa testemunho de concretizações acontecidas ao longo do e no tempo histórico.

O Ensino de Ciências no Ensino Fundamental apresenta grandes desafios: instigar a curiosidade de maneira orientada e organizada, utilizar linguagem acessível, desenvolver o interesse pela natureza e pela ciência. O desenvolvimento de habilidades proporciona a formação de cidadãos reflexivos, críticos, capazes de entender o mundo e interagir com ele, e aptos a tomar decisões em benefício do aprendizado e da comunidade. No momento atual, o pensamento crítico e a compreensão das tecnologias são essenciais para a vida, constituindo atributos fundamentais a serem adquiridos na educação básica.

Dessa forma, objetiva-se propor uma sequência didática para desenvolver a Educação Ambiental de maneira interdisciplinar, integrando todas as áreas de conhecimento, de acordo com a BNCC (Brasil, 2017). Vale ressaltar que o professor exerce papel determinante de mediador entre aluno e conhecimento.

Essa proposta de metodologia é um importante recurso para os processos de ensino e de aprendizagem, pois visa interligar a interdisciplinaridade com a Educação Ambiental, de uma maneira diferenciada e instigante.

\section{Aspectos Teóricos}

\subsection{Interdisciplinaridade}

A preocupação com uma visão mais integrada e articulada de diversas formas de apreensão da realidade - os diversos ramos do conhecimento humano - conduzem, mais recentemente, à tentativa de construção de procedimentos pedagógicos que busquem a superação da fragmentação do ensino e da própria produção científica. A visão especializada do mundo é determinada pelo paradigma positivista disciplinar, em que a realidade representa um todo regular, estável e acabado. Os fenômenos reais são compreendidos isoladamente sob uma lógica dedutiva. Não há uma análise do fato real sobre um contexto.

A concepção fragmentada promove, sob o campo pedagógico, um tratamento descontextualizado do conhecimento, privando ao educando da possibilidade de compreender o mundo sobre um movimento dialético entre sua própria posição como sujeito histórico e o resultado de ações coletivas conflituosas e contraditórias.

Segundo Freire (1987b), essa concepção fragmentada é definida pela visão "bancária” da educação, em que o "saber" é uma doação dos que se julgam sábios aos que julgam nada saber. A educação "bancária” considera a educação como o ato de depositar, de transferir, de transmitir valores, informações e conhecimentos. Assim, a escola reflete uma sociedade opressora, configurando-se na dimensão da "cultura do silêncio".

O educador é aquele que educa; os educandos, os que são educados. O educador é aquele que sabe; os educandos, os que não sabem. O educador é o que pensa; os educandos, os pensados. O educador é o que diz a palavra; os educandos, os que escutam docilmente. O educador é o que disciplina; os educandos, os disciplinados. O educador é o que atua; os educandos, os que têm ilusão de que atuam, na atuação do professor. (Freire, 1996, p. 34)

Percebe-se, nessa citação de Freire (1996), que aluno e professor vivenciam uma relação de autoritarismo, em que o professor manda e o aluno executa, caracterizando a verticalidade da relação entre professor e aluno, caracterizando, assim, a “educação bancária", que reflete as características de uma sociedade industrial. Como atitude de superação desse paradigma disciplinar, busca-se uma dimensão interdisciplinar no campo da ciência e do ensino. A metodologia de construção do conhecimento tenciona a aproximação do entendimento de mundo pela totalidade, pela unidade, em que os fenômenos naturais, sociais e culturais sejam apreendidos em inter-relação. 
A interdisciplinaridade, no campo da Ciência, corresponde à necessidade de superar a visão fragmentadora de produção do conhecimento, como também de articular e produzir coerência entre os múltiplos fragmentos que estão postos no acervo de conhecimentos da humanidade. Trata-se de um esforço no sentido de promover a elaboração de síntese que desenvolvam a contínua recomposição da unidade entre as múltiplas representações da realidade. (Lück, 2013, p. 59)

A vivência da interdisciplinaridade ainda precisa ser incorporada por espaços de produção acadêmica. Os profissionais egressos das universidades atuaram em conformidade aos processos de formação a que foram submetidos. Nessa direção epistemológica e metodológica, deverão caminhar os currículos acadêmicos, para que as práticas profissionais sejam pautadas por um caráter totalizador de produção e/ou reprodução do conhecimento.

A complexidade da docência acontece pela relação desses saberes entre si, articulados com as estratégias didáticas e a relação do conteúdo pelo qual se ensina com o contexto da profissão. "A estratégia é aberta, evolutiva, enfrenta o imprevisto, o novo. O programa não improvisa nem inova, mas a estratégia sim. [...] A estratégia não só necessita deles, mas também, a todo o momento, de concorrência, iniciativa, decisão e reflexão (Morin, 2003, p. 29). Cunha (2010, p. 22) refere que “os diferentes saberes que compõem a dimensão pedagógica da docência se articulam entre si e definem dependências recíprocas [...] são mobilizados saberes indicativos da complexidade da docência, envolvem uma complexidade de docência".

A Base Nacional Comum Curricular (BNCC) é um documento de caráter normativo que define o conjunto orgânico e progressivo de aprendizagens essenciais que todos os estudantes devem desenvolver ao longo das etapas e modalidades da Educação Básica, de modo a que tenham assegurados seus direitos de aprendizagem e desenvolvimento, em conformidade com o que preceitua o Plano Nacional de Educação (PNE) (Brasil, 2017). De acordo com os fundamentos pedagógicos apresentados na Introdução desse documento, a BNCC está estruturada de modo a explicitar as competências que os estudantes devem desenvolver ao longo de toda a Educação Básica e em cada etapa da escolaridade, como expressão dos direitos de aprendizagem e desenvolvimento de todos os estudantes (Brasil, 2017).

Na BNCC, o Ensino Fundamental está organizado em cinco áreas do conhecimento: área de linguagens, área de matemática, área de ciências da natureza, área de ciências humanas e área de ensino religioso. Essas áreas, como bem aponta o Parecer CNE/CEB n ${ }^{\circ}$ 11/2010, "favorecem a comunicação entre os conhecimentos e saberes dos diferentes componentes curriculares" (Brasil, 2010). Elas se intersectam na formação dos estudantes, embora se preservem as especificidades e os saberes próprios construídos e sistematizados nos diversos componentes. Em consonância com os princípios da BNCC, é importante que se busque contemplar em seus currículos o ensino interdisciplinar, que pode ocorrer por meio de atividades que integrem o conhecimento vivo e dialogado entre diferentes áreas.

A interdisciplinaridade pode ser compreendida como sendo uma troca de reciprocidade entre as disciplinas ou ciências, ou melhor, de áreas do conhecimento. O prefixo "inter”, entre os vários conceitos que podemos lhe atribuir, tem o significado de "troca", "reciprocidade" e "disciplina", de "ensino", "ciência" (Ferreira, 2011, p. 22). A interdisciplinaridade proporciona a condição de compreender os elementos relevantes que constituem o todo de uma forma interconectada, agregada à singularidade-subjetividade-complexidade de cada componente curricular proveniente do conjunto de dados com significado, por meio da temática estudada.

Nessa perspectiva, é necessário ter a compreensão de como o conhecimento se constrói. Com base em Morin (2012), o conhecimento constitui um processo de reconstrução, a partir de sinais, signos, símbolos, sob a forma de representações, ideias, teorias, discursos. A organização dos conhecimentos é realizada por meio de princípios que compõem a ligação e a separação. Assim, para Morin (2012, p. 24), “o processo é circular, passando da separação à ligação, da ligação à separação e, além disso, da análise à síntese, da síntese à análise. Ou seja: o conhecimento comporta, ao mesmo tempo, separação e ligação, análise e síntese”. 
Nesse sentido, os processos de ensino e de aprendizagem pautados no pensamento complexo, perpassam pela trajetória, mencionada por Morin et al. (2003, p. 34): “o método, visto como caminho/ensaio/estratégia contém um conjunto de princípios metodológicos que configuram um guia para um pensar complexo". Então, a trajetória experiência os processos de ensino e de aprendizagem, vivenciada entre as partes, e o todo se dá na disjunção das partes, e a religação ocorre a partir das conexões conceituais no todo da sequência didática, pois "o todo só funciona como todo se as partes funcionarem como partes. O todo deve estar relacionado com a organização" (Morin, 1997, p. 122).

A experiência interdisciplinar na prática pedagógica vivenciada como forma de desenvolver um trabalho de integração e articulação de conteúdo de um componente curricular com outras áreas de conhecimento é uma proposta que contribui para o aprendizado global do estudante, porque, assim, ele tem a visão do todo e das especificidades que se fundem em um tema ou conteúdo articulador.

\subsection{Educação Ambiental}

A Educação Ambiental integra o campo educativo. A construção da Educação Ambiental envolve um saber amplo, um “saber”, conceitos e princípios, um “saber fazer”, habilidades, e um “saber ser”, valores e atitudes. Portanto, segundo Grüm (1994, p. 171), “a Educação Ambiental se dá no encontro entre valores de conservação das comunidades bióticas, abióticas e sociais provenientes destes valores. Essas esferas estão mutuamente informadas, constituindo o "campo educativo". A Educação Ambiental deverá ocorrer em associação a princípios fundamentais de participação, cidadania, autonomia, intimidade à cultura local e sustentabilidade. Uma educação que priorize estes princípios, em suas bases epistemológicas e metodológicas, estará formando seres humanos preparados para os desafios que a realidade socioambiental vem impondo à obtenção da qualidade social necessária à emancipação social.

A produção participativa aguça a formação de uma consciência social, por uma postura reflexiva frente à realidade conflituosa e que exige a busca por superação dos problemas encontrados. Pois é na prática social que emergirão novos saberes, novos olhares, novos valores numa original prática educativa. Assim conclui-se que

A Educação Ambiental exige uma postura crítica e um corpo de conhecimentos produzido a partir de uma reflexão sobre a realidade vivenciada. Sendo uma proposta essencialmente comunitária, materializa-se através de uma prática cujo objetivo maior é a promoção de um comportamento adequado à proteção ambiental. Comporta uma concepção desalienante, porquanto pressupõe ações voltadas para o surgimento de novos valores, onde a participação é um princípio fundamental. (Lima, 1984, p. 23)

Que função se atribui à Educação Ambiental nesse contexto histórico-cultural que presenciamos? A função primeira da Educação Ambiental reside no papel de integradora dos sistemas educativos de que dispõe a sociedade, bem como instrumento de tomada de consciência do fenômeno do desenvolvimento e suas implicações ambientais e de transmissão de conhecimentos, habilidades e experiências que permitam ao homem atuar eficientemente no processo de manutenção ou recuperação do equilíbrio ambiental, de forma a manter uma qualidade de vida condizente com suas necessidades e aspirações. Deve representar um processo que visa formar uma sociedade consciente e preocupada com o ambiente e os problemas que lhe dizem respeito, uma sociedade que tenha os conhecimentos, a intencionalidade, as motivações e o sentido de participação e engajamento que lhe permitam agir individualmente e coletivamente para resolver os problemas atuais e impedir que se repitam. Deve compreender um processo permanente e participativo de explicitação de valores, instrução sobre problemas específicos relacionados com o meio ambiente, formação de conceitos e aquisição de conhecimentos que motivem o comportamento de defesa, preservação e melhoria do ambiente acima de tudo social. 
Pensar Educação Ambiental prescinde pensar uma educação que promova conscientização. Nesse contexto, segundo Freire (1995, p. 19), “na educação como façanha da liberdade, ser consciente não é uma fórmula ou um 'slogan', mas a forma de estar sendo dos seres humanos, enquanto seres que não apenas conhecem, mas sabem que conhecem".

A Educação Ambiental deve representar instrumento ao desenvolvimento da consciência das coisas e dos fatos que rodeiam o ser humano. A consciência deste mundo incita, também, a consciência de que se pode mudá-lo. Ao refazer este mundo, o homem também se refaz. Nas palavras de Freire (1987a, p. 14), a seguir, evidencia-se a importância de priorizar a vida frente à existência humana:

Nós temos de colocar a existência decentemente frente à vida, em sua contradição com a vida, em sua dialeticidade, de tal maneira que a existência não mate a vida e que a vida não pretenda acabar com a existência, para se defender dos riscos que a existência lhe impõe. (Freire, 1987a, p. 14)

Tratar a caminhada de formação de uma consciência ambiental requer postular uma educação que impulsione a sociedade à descoberta de mecanismos que mobilizem ao exercício de cidadania. É sabido que a política educacional brasileira reflete aspectos que condicionaram historicamente a evolução do ensino no Brasil, envolvendo a herança cultural, o modelo econômico e as relações de poder. Portanto, as Políticas Educacionais no Brasil estão servindo à manutenção dos detentores do poder econômico. Lutar para transformar essa realidade socioambiental perpassa a consciência de cidadania. Que cidadania? Cidadania como princípio democrático.

Cidadania trata-se da consciência dos direitos democráticos, é a prática de quem está ajudando a construir valores. Em nossa sociedade, significa a mobilização em busca da mudança de estruturas injustas onde uns são beneficiados em detrimento da grande maioria. É a luta pela transformação da realidade, através da elaboração de propostas, da crítica de ações inadequadas e da promoção da solidariedade. (Medeiros, 1997, p. 56)

Uma educação crítico-reflexiva, comprometida com a realidade iminente, agregadora, humanizadora, marcada na liberdade e autonomia poderá dar suporte e mobilizador à cidadania. Cidadania, que qualifique democraticamente o Estado em que a equalização social seja uma realidade.

A educação não favorece a imediata cidadania. A educação funciona como processo formador de consciências para a ação coletiva "em ambiente solidário", para uma ação participativa e interventora na sociedade. Aproximar-se de um projeto nacional emancipatório exige confronto, consciência crítica contestatória, busca pela condução do destino histórico, formação de um projeto próprio de desenvolvimento e ocupação de espaços sociais pela massa popular. O sujeito emancipado luta por direitos sociais, tendo a ética e as relações humanas como fundamento da conquista.

A ética que confunde a consciência de si e consciência do outro, que aproxima consciência de existência, vem instaurar um outro princípio fundamental do processo emancipatório - a autonomia. Uma autonomia desejada e concebida pelo esforço de todos e para todos. Uma autonomia que implica participação consciente no mundo. É a assunção consciente do que é verdadeiro e o que se deseja na caminhada por libertação. Autonomia, participação e cidadania são fundamentos estruturais da práxis ambiental como produção resultante de uma sensibilização e conscientização ambiental.

A Educação Ambiental, vista na dimensão que se acredita, incorpora a possibilidade de superação dos problemas socioambientais pela modificação do modelo social, no qual uma nova sociedade venha conciliar as relações dos homens entre si e deles com a natureza, em uma tentativa de atingir sustentabilidade. A sustentabilidade não pode ser analisada de forma dissociada do contexto econômico neoliberal. A garantia de sustentabilidade está subordinada ao modelo de desenvolvimento coordenado por nações desenvolvidas, quando dita às nações subdesenvolvidas, sistemas produtivos que vinculam desenvolvimento à apropriação consumista de recursos naturais e humanos. Portanto, atingir sustentabilidade requer uma 
revisão conjuntural do modelo político-econômico e social que vigora no país. Portanto, quando se considera Desenvolvimento Sustentável como aquele que atende às necessidades presentes sem comprometer a capacidade de as gerações futuras também atenderem às suas, vale levar em conta a contribuição decisiva do processo educativo na formação de consciências cidadãs; de tal forma que, em longo prazo, se obtenha-se uma sociedade e um Estado compostos por líderes representativos da vontade popular e que revelem consciência pública perante o rumo desenvolvimentista das próximas gerações.

O ponto de partida deste estudo envolveu a sensibilização e compreensão de que atingir consciência ambiental exige o exame de aspectos, como libertação, participação, autonomia e cidadania, como pressupostos inerentes ao ato educativo, e que são condicionamentos fundamentais à formação de uma sociedade diferente e emancipada e que atinja qualidade socioambiental.

Assim como o desvelamento de muitas questões sociais, a Educação Ambiental deve ser construída de forma consciente, participativa, autônoma e cidadã também no meio rural. O ser humano é produto do mundo e, neste mundo, busca renovação, aperfeiçoamento. A forma de vida do homem vai concretizando a forma histórica que lhe atribui uma cultura própria. O fenômeno educacional encontra-se profundamente relacionado com os fatos fundamentais que constituem o cerne da sociedade, quais sejam, a produção, a reprodução e a transformação social, o que leva a perceber a dimensão histórica da educação, possibilitando que ela mesma se modifique e que também contribua para a transformação social, pois os grupos humanos elaboram não apenas bens materiais, mas também bens culturais, diretamente ligados à sua existência.

O lugar pode ser definido como o espaço percebido, ou seja, uma determinada área ou ponto do espaço da forma como são entendidos pela razão humana. Seu conceito também se liga ao espaço afetivo, aquele local com o qual uma determinada pessoa tem certa familiaridade ou intimidade, como uma rua, uma praça ou a própria casa (Brasil Escola, 2016).

Os plásticos são materiais poliméricos com aplicação comercial, sólidos à temperatura ambiente e geralmente moldáveis com temperatura, podendo ser classificados quanto a suas propriedades mecânicas, composição química e capacidade de moldagem (Infoescola, 2005).

Mas o que a Educação Ambiental tem a ver com o lugar e com o plástico? Uma educação para o cuidado com o meio ambiente deve iniciar com atitudes de proteção aos elementos naturais e sociais, do lugar o qual se pertence, e, em especial, dando atenção ao plástico por meio do conhecimento do uso e destino correto que se deve dar a ele.

De acordo com a Lei 9.795/1999, art. 1º, entende-se por Educação Ambiental os processos por meio dos quais o indivíduo e a coletividade constroem valores sociais, conhecimentos, habilidades, atitudes e competências voltados para a conservação do meio ambiente, bem de uso comum do povo, essencial à sadia qualidade de vida e sua sustentabilidade.

Considerando a presença do plástico em praticamente todos os setores da economia, seu impacto sobre as atividades humanas, a ciência e a tecnologia por trás da sua manufatura e da gestão de seus resíduos, é inegável as inúmeras possibilidades de abordagem interdisciplinar que esse tema oferece. História, ciência e tecnologia do plástico constituem, portanto, um rico material para abordar também a questão da gestão sustentável dos recursos naturais. Ademais, parte dos conceitos técnicos e científicos que envolvem manufatura, descarte e reutilização necessitam ser parte das aprendizagens essenciais estabelecidas no currículo escolar nas diferentes etapas da educação básica (Piatti \& Ferreira, 2005). Isso abre portas para que os temas relacionados ao plástico possam ser objeto de prática interdisciplinar conectados aos fazeres e saberes escolares, organizados por meio de Sequência Didática.

\section{Proposta Metodológica}

A presente proposta foi estrutura a partir do projeto de pesquisa intitulado "Ciência e tecnologia do plástico: um argumento para construção de espaços colaborativos de ensino e da abordagem de práticas sustentáveis na educação básica", financiada pelo CNPq por meio do Programa Ciência na Escola. 
O público-alvo da pesquisa são professores e estudantes do sexto e sétimo ano, de uma Escola Municipal de Ensino Fundamental, do município de Santa Maria, Rio Grande do Sul, Brasil.

Nesse estudo optou-se pela abordagem qualitativa, que permite compreender o estudo a partir de experiências e comportamentos vividos pelos sujeitos.

A abordagem metodológica é qualitativa, e o tipo de pesquisa empreendida envolve a pesquisa ação, uma vez que os sujeitos investigados se encontram inseridos nas ações de programação e planejamento de ações compartilhadas com a comunidade escolar, bem como diante de momentos integrados de intervenção sobre o recorte espacial, compreendido pelo entorno da escola.

Para Thiollent (2009, p. 16), Metodologia da Pesquisa-ação, é compreendida como uma: "um tipo de pesquisa social com base empírica que é concebida e realizada em estreita associação com uma ação ou com a resolução de um problema coletivo e no qual os pesquisadores e os participantes representativos da situação ou do problema estão envolvidos de modo cooperativo ou participativos".

A sequência didática é uma estratégia de ensino que consiste em estratégias planejadas e desenvolvidas com base em conceitos científicos que se ajustam ao interesse e ao saber prévio dos educandos, possibilitando verificar como os sujeitos interagem e o que aprendem sobre temas relacionados (ZABALA, 1998).

Assim, para o desenvolvimento desta proposta, sugere-se uma sequência didática elaborada em torno de um tema norteador. A sequência de atividades sugeridas foi estruturada tendo como norte a ciência e tecnologia do plástico e os impactos socioambientais decorrentes do advento e do consumo desse material. A sequência permite discutir a relevância do plástico na sociedade contemporânea, os impactos ambientais negativos decorrentes do consumo excessivo e do descarte inadequado desse material e o valor do resíduo plástico para comunidades e para indústria, abordando os temas da reciclagem e reutilização desse material. No Quadro 1, constam os momentos e as proposições pedagógicas da sequência didática.

Quadro 1 - Momentos e proposições pedagógicas da sequência didática.

\begin{tabular}{|c|c|c|}
\hline Momentos & Disciplina(s) do currículo escolar/abrangência & Proposição pedagógica \\
\hline Integrado & Noções conceituais de todos os conhecimentos escolares. & $\begin{array}{c}\text { Investigação dos conhecimentos prévios } \\
\text { dos estudantes }\end{array}$ \\
\hline Disciplinar & Conhecimentos matemáticos & $\begin{array}{c}\text { Produção de gráficos a partir de uma } \\
\text { reportagem }\end{array}$ \\
\hline Disciplinar & Conhecimentos de linguagens & Criação de post para redes sociais \\
\hline Disciplinar & Conhecimentos filosóficos e religiosos & Reflexões sobre filosofia de vida \\
\hline Disciplinar & Conhecimentos geográficos & Impactos ambientais \\
\hline Disciplinar & Conhecimentos artísticos & Produção artística \\
\hline Integrado & Noções conceituais de todos os conhecimentos escolares & Desafio da trilha \\
\hline Integrado & Noções conceituais de todos os conhecimentos escolares & Desenvolvendo ações ambientais \\
\hline Disciplinar & Conhecimentos históricos & $\begin{array}{l}\text { Discussão das lógicas comerciais da } \\
\text { modernidade }\end{array}$ \\
\hline Disciplinar & Conhecimentos artísticos e de linguagem & Musicalidade \\
\hline Integrado & Noções conceituais de todos os conhecimentos escolares. & Fórum on-line \\
\hline
\end{tabular}

Fonte: Elaborado pelos autores.

A seguir, consta a descrição de cada etapa da sequência didática, bem como das atividades sugeridas. 
Momento Integrado: Investigação dos conhecimentos prévios dos estudantes:

$\mathrm{Na}$ primeira etapa, com noções conceituais de todos os conhecimentos escolares. Para a investigação dos conhecimentos prévios, sugere-se, inicialmente, mostrar aos estudantes a Figura 1, que foi registrada sobre a grade de proteção de uma residência, no Bairro Nossa Senhora do Perpétuo Socorro, na cidade de Santa Maria, Rio Grande do Sul, Brasil.

Figura 1 - Imagem de resíduos sólidos coletados, embalados e disponibilizados para recolhimento, em residência do Bairro Nossa Senhora do Perpétuo Socorro, Santa Maria, RS, Brasil.

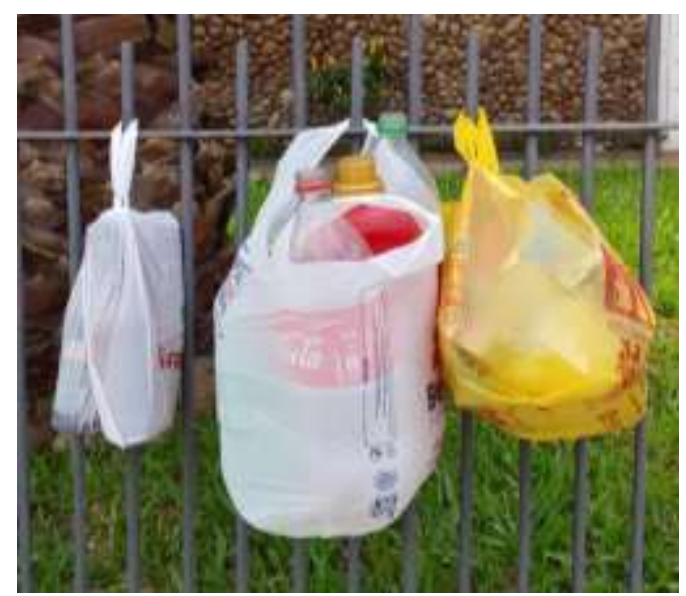

Fonte: Arquivo dos autores.

Após, alguns questionamentos poderão ser feitos, como: Você mora neste bairro? Você conhece as belezas naturais de seu bairro? Você observa problemas ambientais no bairro? Você colabora com sua família na seleção do lixo doméstico? O que é lixo "orgânico"? O que é lixo "seco"? O que são "resíduos sólidos”? Como você interpreta a atitude de separar o lixo "seco" do lixo "orgânico"?

Dessa forma, os conhecimentos prévios dos estudantes poderão ser investigados em todas as disciplinas escolares e registrados.

Momento Disciplinar: Produção de gráficos a partir de uma reportagem.

No componente curricular Matemática, será disponibilizada uma reportagem pelo link: https:/g1.globo.com/natureza/noticia/2020/10/05/pandemia-do-plastico-covid-19-joga-no-lixo-sonho-da-reciclagem.ghtml. A partir da leitura da reportagem, serão analisados os percentuais indicados e criados gráficos com dados sobre produção, volume, destino de resíduos de plásticos.

Momento Disciplinar: Criação de post para redes sociais.

No componente curricular Língua Portuguesa, serão propostas atividades com o uso de tecnologias educacionais, uma vez que, agora, a tecnologia digital está sendo muito utilizada. Neste momento da sequência didática, os estudantes realizarão a criação de post para disponibilizarem em suas redes sociais, sobre temática relacionada à preservação do meio ambiente, por meio do aplicativo Fotor editor, gratuito, e que pode ser acessado em celulares e/ou computador. A produção dos posts deverá envolver uma imagem, registrada sobre espaços do bairro, abordando locais que revelam ações positivas de preservação ambiental e/ou atitudes de não cuidado ou preservação dos recursos ambientais, com uma frase produzida pelos próprios estudantes. A produção das frases evidenciará a produção autoral. 
Momento Disciplinar: Reflexões sobre filosofia de vida.

O componente curricular Ensino Religioso promoverá uma análise crítica das relações de diferentes grupos, povos e sociedades com a natureza (produção, distribuição e consumo) e seus impactos econômicos e socioambientais, com vistas à proposição de alternativas que respeitem e promovam a consciência, a ética socioambiental e o consumo responsável em âmbito local, regional, nacional e global. Essa reflexão será registrada por meio de slogns e/ou pequenos textos.

Momento Disciplinar: Impactos ambientais.

No componente curricular Geografia, será proposta uma pesquisa sobre os impactos ambientais causados pelos resíduos de plásticos e pela decomposição dos materiais no meio ambiente.

Momento Disciplinar: Produção artística.

Nesse momento, sugere-se a produção artística, a partir do plástico, com o viés da intervenção urbana, momento em que os estudantes podem produzir obras artísticas com o objetivo de sensibilizar para a Educação Ambiental.

Momento Integrado: Desafio da trilha.

Essa etapa será destinada para um desafio, em que se questiona ao aluno: Se você fosse organizar uma trilha no Bairro Nossa Senhora do Perpétuo Socorro, que pontos você marcaria para visitação de um grupo de pessoas de várias idades? Indique quais pontos do Bairro. Enumere aspectos saudáveis da participação em uma trilha ecológica. Acesse a trilha Sustentageo: https://pt.wikiloc.com/trilhas-trekking/sustentageo-14288111\#morePhoto, para conhecimento.

Momento Integrado: Desenvolvendo ações ambientais.

Nesse momento, ocorrerá o desenvolvimento de propostas de ações sobre as questões ambientais, direcionado aos impactos ambientais dos resíduos de plásticos. Os estudantes podem ser desafiados a pensar em ações direcionadas à redução do consumo de materiais plásticos e ao descarte correto de resíduos, que possam ser implementadas no âmbito de sua comunidade familiar e escolar. Devem pensar, em equipes, sobre como executá-las e, tendo definido os métodos e o público alvo dessas ações, implementá-las. É interessante que os estudantes possam definir índices para monitorar os resultados de suas ações. Depois de um tempo, devem avaliar os resultados, também por meio dos índices, e discutir se a ação foi ou não efetiva, o que foi fácil e difícil de ser implementado e o que poderia ser melhorado.

Momento Disciplinar: Discussão das lógicas comerciais da modernidade.

Esse momento tem como objetivo proporcionar a discussão com relação às lógicas comerciais e mercantis da modernidade e a emergência do capitalismo, no componente curricular História.

Nessa etapa, o professor pode identificar características no modo de consumo atual a partir do diálogo com os estudantes e questioná-los se seus pais e avós seguiam os mesmos hábitos. Junto, discentes e docentes podem elaborar um questionário, nos moldes de uma pesquisa qualitativa, para ser realizado com pessoas mais idosas.

\section{Momento Disciplinar: Musicalidade.}

Esse momento tem como objetivo proporcionar aos estudantes o conhecimento de músicas que propagam a preservação da natureza, proporcionando o conhecimento de movimentos sociais nacionais e internacionais de luta pela preservação ambiental. 
Momento Integrado: Fórum on-line com segmentos da comunidade escolar.

O encerramento da sequência didática poderá ser realizado por meio de uma "mostra de arte e ciência", em que os estudantes possam apresentar para a comunidade todos os resultados das atividades, com debates com a participação de professores convidados, no ambiente virtual de aprendizagem - Moodle, da Escola.

\section{Discussões}

A sequência didática proposta revelou evidências relevantes diante dos momentos basilares de construção. Cabe destacar que estudo apenas propõe a sequência didática para uma possível aplicação com o público-alvo.

\subsection{Momentos integrados}

A proposta objetivou mobilizar para a construção de saberes, fazeres e atitudes em torno da ciência e tecnologia do plástico e os impactos socioambientais decorrentes do advento e do consumo desse material.

O lançamento de temática "EDUCAÇÃO AMBIENTAL: LUGAR X PLÁSTICO. OBJETIVOS PARA O DESENVOLVIMENTO SUSTENTÁVEL NA AGENDA 2030 DA ONU” constituiu motivo mobilizador para a construção de saberes e fazeres articulados, em consonância como sentido da interdisciplinaridade. O planejamento das atividades pedagógicas foi pensado de forma a ocorrer uma conjunção de noções conceituais de importantes interfaces, que contribuíram para a compreensão de fatores de origem, funcionalidade e efeitos implicados na relação entre Educação Ambiental, lugar, plástico e desenvolvimento sustentável. Todas as áreas do currículo escolar foram chamadas para estabelecer conexões necessárias à produção de um conhecimento amplo, que revela movimento consiste e agregador entre saberes, fazeres e modos de ser.

Nos momentos integrados, pôde-se verificar as noções conceituais de todos os conhecimentos escolares por meio da investigação dos conhecimentos prévios.

A Figura 1, apresentada no item 3, foi uma imagem instigadora em que o estudante observa o descarte e armazenamento de alguns resíduos plásticos domiciliares.

O "Desafio da trilha" poderá ser um recurso para que o aluno conheça o seu bairro e também crie o hábito da observação dos locais ao seu redor.

O momento "Desenvolvendo ações ambientais" oportunizará ao estudante um momento para desenvolver e pensar em ações direcionadas ao consumo consciente do plástico, bem como a redução do seu consumo.

O último momento integrado, na forma de um fórum on-line, constitui o encerramento da sequência didática, em que, por meio de uma mostra de arte de ciências, os estudantes poderão contextualizar todas as atividades realizadas, além de refletir e debater sobre o tema relacionado aos plásticos.

\subsection{Momentos disciplinares}

O momento disciplinar denominado "Produção de gráficos a partir de uma reportagem" contempla o componente curricular Matemática, em que os estudantes poderão desenvolver e produzir gráficos a partir de uma reportagem, de acordo com a unidade temática Probabilidade e estatística.

A criação de post para redes sociais possibilitará o uso de tecnologias digitais relacionadas a preservação do meio ambiente, englobando o componente curricular Língua Portuguesa, na unidade temática Práticas de Linguagem: produção de textos. 
As reflexões sobre a filosofia de vida visam a uma análise crítica das relações socioculturais e os seus impactos ambientais, de modo a contemplar o Ensino Religioso, conforme a unidade temática Crenças religiosas e filosofias de vida.

O componente curricular Geografia, na unidade temática Natureza, ambientes e qualidade de vida, poderá estar relacionado a uma pesquisa sobre os impactos ambientais causados pelo descarte dos resíduos plásticos. Vale ressaltar que o tempo de decomposição e a degradação desses materiais também poderá ser relacionado com os impactos ambientais.

A produção artística, por meios dos conhecimentos adquiridos no decorrer da proposta, considerando a importância do plástico na Educação Ambiental, poderá fazer parte do componente curricular Artes, na unidade temática Artes visuais.

O componente curricular História poderá ser trabalhado por meio do diálogo e de questionamentos sobre o consumo atual e passado do plástico, de acordo com a unidade temática Lógicas comerciais e mercantis da modernidade.

A musicalidade será um recurso para o componente curricular Língua Inglesa, em que as músicas nacionais e internacionais serão recursos para desenvolver o aprendizado, conforme o eixo Leitura: práticas de leitura e pesquisa.

A área das Ciências da Natureza é o eixo norteador de toda a proposta, pois engloba o estudo de todos os aspectos relacionados à natureza, e a unidade temática Vida e evolução tem como objeto de conhecimento os Fenômenos naturais e impactos ambientais, que corrobora esse estudo.

No Quadro 2, constam as unidades temáticas, os objetos de conhecimento, a habilidade e a competência específica de cada área do conhecimento.

Pode-se observar que a proposta da sequência didática interdisciplinar contempla as cinco áreas do conhecimento: matemática, linguagem, ensino religioso, ciências da natureza e ciências humanas, bem como as disciplinas de cada área, de maneira com que as atividades se enquadrem em um objeto de conhecimento, contemplando uma habilidade e uma competência específica do Ensino Fundamental. 
Quadro 2 - Unidades temáticas, objetos de conhecimento, habilidade e competência específica de cada área do conhecimento.

\begin{tabular}{|c|c|c|c|c|c|c|c|c|}
\hline \multirow{2}{*}{$\begin{array}{c}\text { Área } \\
\text { Disciplina }\end{array}$} & \multirow{2}{*}{$\begin{array}{l}\text { Matemática } \\
\text { Matemática }\end{array}$} & \multicolumn{3}{|c|}{ Linguagem } & \multirow{2}{*}{$\begin{array}{c}\begin{array}{c}\text { Ensino } \\
\text { Religioso }\end{array} \\
\text { Ensino } \\
\text { Religioso }\end{array}$} & \multirow{2}{*}{$\begin{array}{c}\begin{array}{c}\text { Ciências da } \\
\text { Natureza }\end{array} \\
\text { Ciências }\end{array}$} & \multicolumn{2}{|c|}{ Ciências Humanas } \\
\hline & & Língua Portuguesa & Arte & $\begin{array}{l}\text { Língua } \\
\text { inglesa }\end{array}$ & & & Geografia & História \\
\hline $\begin{array}{l}\text { Unidade } \\
\text { temática }\end{array}$ & Probabilidade e estatística & $\begin{array}{l}\text { Práticas de linguagem: } \\
\text { Produção de textos }\end{array}$ & Artes visuais & $\begin{array}{l}\text { Eixo leitura: } \\
\text { Práticas de } \\
\text { leitura e } \\
\text { pesquisa }\end{array}$ & $\begin{array}{l}\text { Crenças } \\
\text { religiosas e } \\
\text { filosofias de } \\
\quad \text { vida. }\end{array}$ & Vida e evolução & $\begin{array}{c}\text { Natureza, } \\
\text { ambientes e } \\
\text { qualidade de vida }\end{array}$ & $\begin{array}{c}\text { Lógicas comerciais } \\
\text { e mercantis da } \\
\text { modernidade }\end{array}$ \\
\hline $\begin{array}{l}\text { Objetos de } \\
\text { conhecimento }\end{array}$ & $\begin{array}{c}\text { Gráficos de setores: } \\
\text { interpretação, pertinência e } \\
\text { construção para representar } \\
\text { conjunto de dados }\end{array}$ & $\begin{array}{l}\text { Produção e edição de } \\
\text { textos publicitários }\end{array}$ & $\begin{array}{l}\text { Processos de } \\
\text { criação }\end{array}$ & $\begin{array}{l}\text { Leitura de } \\
\text { textos digitais } \\
\text { para estudo }\end{array}$ & $\begin{array}{l}\text { Princípios éticos } \\
\text { e valores } \\
\text { religiosos. }\end{array}$ & $\begin{array}{c}\text { Fenômenos } \\
\text { naturais e impactos } \\
\text { ambientais }\end{array}$ & $\begin{array}{l}\text { Biodiversidade } \\
\text { brasileira }\end{array}$ & $\begin{array}{l}\text { A emergência do } \\
\text { capitalismo }\end{array}$ \\
\hline Habilidade & $\begin{array}{l}\text { (EF07MA37) } \\
\text { Interpretar e analisar dados } \\
\text { apresentados em gráfico de } \\
\text { setores divulgados pela } \\
\text { mídia e compreender } \\
\text { quando é possível ou } \\
\text { conveniente sua utilização. }\end{array}$ & $\begin{array}{l}\text { (EF67LP13) } \\
\text { Produzir, revisar e } \\
\text { editar textos } \\
\text { publicitários, levando } \\
\text { em conta o contexto de } \\
\text { produção dado, } \\
\text { explorando recursos } \\
\text { multissemióticos, } \\
\text { relacionando elementos } \\
\text { verbais e visuais, } \\
\text { utilizando } \\
\text { adequadamente } \\
\text { estratégias discursivas } \\
\text { de persuasão e/ou } \\
\text { convencimento e } \\
\text { criando título ou slogan } \\
\text { que façam o leitor } \\
\text { motivar-se a interagir } \\
\text { com o texto produzido e } \\
\text { se sinta atraído pelo } \\
\text { serviço, ideia ou } \\
\text { produto em questão. }\end{array}$ & $\begin{array}{l}\text { (EF69AR06) } \\
\text { Desenvolver } \\
\text { processos de } \\
\text { criação em } \\
\text { artes visuais, } \\
\text { com base em } \\
\text { temas ou } \\
\text { interesses } \\
\text { artísticos, de } \\
\text { modo } \\
\text { individual, } \\
\text { coletivo e } \\
\text { colaborativo, } \\
\text { fazendo uso } \\
\text { de materiais, } \\
\text { instrumentos e } \\
\text { recursos } \\
\text { convencionais } \\
\text { alternativos e } \\
\text { digitais. }\end{array}$ & $\begin{array}{l}\text { (EF07LI09) } \\
\text { Selecionar, } \\
\text { em um texto, } \\
\text { a informação } \\
\text { desejada } \\
\text { como objetivo } \\
\text { de leitura. }\end{array}$ & $\begin{array}{l}\text { (EF07ER06) } \\
\text { Identificar } \\
\text { princípios éticos } \\
\text { em diferentes } \\
\text { tradições } \\
\text { religiosas e } \\
\text { filosofias de } \\
\text { vida, discutindo } \\
\text { como podem } \\
\text { influenciar } \\
\text { condutas } \\
\text { pessoais e } \\
\text { práticas sociais. }\end{array}$ & $\begin{array}{l}\text { (EF07CI08) Avaliar } \\
\text { como os impactos } \\
\text { provocados por } \\
\text { catástrofes naturais } \\
\text { ou mudanças nos } \\
\text { componentes } \\
\text { físicos, biológicos } \\
\text { ou sociais de um } \\
\text { ecossistema afetam } \\
\text { suas populações, } \\
\text { podendo ameaçar } \\
\text { ou provocar a } \\
\text { extinção de } \\
\text { espécies, alteração } \\
\text { de hábitos, } \\
\text { migração... }\end{array}$ & $\begin{array}{l}\text { (EF07GE11) } \\
\text { Caracterizar } \\
\text { dinâmicas dos } \\
\text { componentes } \\
\text { físico-naturais no } \\
\text { território nacional, } \\
\text { bem como sua } \\
\text { distribuição e } \\
\text { biodiversidade } \\
\text { (Florestas } \\
\text { Tropicais, } \\
\text { Cerrados, } \\
\text { Caatingas, } \\
\text { Campos Sulinos e } \\
\text { Matas de } \\
\text { Araucária). }\end{array}$ & $\begin{array}{l}\text { (EF07HI17) } \\
\text { Discutir as razões } \\
\text { da passagem do } \\
\text { mercantilismo para } \\
\text { o capitalismo. }\end{array}$ \\
\hline
\end{tabular}


Research, Society and Development, v. 10, n. 5, e15710514808, 2021

(CC BY 4.0) | ISSN 2525-3409 | DOI: http://dx.doi.org/10.33448/rsd-v10i5.14808

\begin{tabular}{|c|c|c|c|c|c|c|c|c|}
\hline Área & Matemática & \multicolumn{3}{|c|}{ Linguagem } & \multirow[b]{2}{*}{\begin{tabular}{l}
\multicolumn{1}{c}{\begin{tabular}{c}
\multicolumn{1}{c}{ Ensino } \\
Religioso
\end{tabular}} \\
Debater, \\
problematizar e \\
posicionar-se \\
frente aos \\
discursos e \\
práticas de \\
intolerância, \\
discriminação e \\
violência de \\
cunho religioso, \\
de modo a \\
assegurar os \\
direitos \\
humanos no \\
constante \\
exercício da \\
cidadania e da \\
cultura de paz.
\end{tabular}} & \multirow[b]{2}{*}{$\begin{array}{l}\quad \begin{array}{c}\text { Ciências da } \\
\text { Natureza }\end{array} \\
\text { Analisar, } \\
\text { compreender e } \\
\text { explicar } \\
\text { características, } \\
\text { fenômenos e } \\
\text { processos relativos } \\
\text { ao mundo natural, } \\
\text { social e tecnológico } \\
\text { (incluindo o digital), } \\
\text { como também as } \\
\text { relações que se } \\
\text { estabelecem entre } \\
\text { eles, exercitando a } \\
\text { curiosidade para } \\
\text { fazer perguntas, } \\
\text { buscar respostas e } \\
\text { criar soluções } \\
\text { (inclusive } \\
\text { tecnológicas) com } \\
\text { base nos } \\
\text { conhecimentos das } \\
\text { Ciências da } \\
\text { Natureza. }\end{array}$} & \multicolumn{2}{|c|}{ Ciências Humanas } \\
\hline $\begin{array}{c}\text { Competência } \\
\text { específica no } \\
\text { Ensino } \\
\text { Fundamental }\end{array}$ & $\begin{array}{l}\text { Compreender as relações } \\
\text { entre conceitos e } \\
\text { procedimentos dos } \\
\text { diferentes campos da } \\
\text { Matemática (Aritmética, } \\
\text { Álgebra, Geometria, } \\
\text { Estatística e Probabilidade) } \\
\text { e de outras áreas do } \\
\text { conhecimento, sentindo } \\
\text { segurança quanto à própria } \\
\text { capacidade de construir e } \\
\text { aplicar conhecimentos } \\
\text { matemáticos, } \\
\text { desenvolvendo a autoestima } \\
\text { e a perseverança na busca de } \\
\text { soluções. }\end{array}$ & $\begin{array}{l}\text { Além das habilidades } \\
\text { de leitura e produção de } \\
\text { textos já consagradas } \\
\text { para o impresso são } \\
\text { contempladas } \\
\text { habilidades para o trato } \\
\text { com o hipertexto e } \\
\text { também com } \\
\text { ferramentas de edição } \\
\text { de textos, áudio e vídeo } \\
\text { e produções que podem } \\
\text { prever postagem de } \\
\text { novos conteúdos locais } \\
\text { que possam ser } \\
\text { significativos para a } \\
\text { escola ou comunidade } \\
\text { ou apreciações e } \\
\text { réplicas a publicações } \\
\text { feitas por outros. }\end{array}$ & $\begin{array}{l}\text { Experienciar a } \\
\text { ludicidade, a } \\
\text { percepção, a } \\
\text { expressividad } \\
\text { e e a } \\
\text { imaginação, } \\
\text { ressignificand } \\
\text { o espaços da } \\
\text { escola e de } \\
\text { fora dela no } \\
\text { âmbito da } \\
\text { Arte. }\end{array}$ & $\begin{array}{l}\text { Utilizar novas } \\
\text { tecnologias, } \\
\text { com novas } \\
\text { linguagens e } \\
\text { modos de } \\
\text { interação, para } \\
\text { pesquisar, } \\
\text { selecionar, } \\
\text { compartilhar, } \\
\text { posicionar-se } \\
\text { e produzir } \\
\text { sentidos em } \\
\text { práticas de } \\
\text { letramento na } \\
\text { língua inglesa, } \\
\text { de forma } \\
\text { ética, crítica e } \\
\text { responsável. }\end{array}$ & & & $\begin{array}{l}\text { Agir pessoal e } \\
\text { coletivamente } \\
\text { com respeito, } \\
\text { autonomia, } \\
\text { responsabilidade, } \\
\text { flexibilidade, } \\
\text { resiliência e } \\
\text { determinação, } \\
\text { propondo ações } \\
\text { sobre as questões } \\
\text { socioambientais, } \\
\text { com base em } \\
\text { princípios éticos, } \\
\text { democráticos, } \\
\text { sustentáveis e } \\
\text { solidários. }\end{array}$ & $\begin{array}{l}\text { Analisar e } \\
\text { compreender o } \\
\text { movimento de } \\
\text { populações e } \\
\text { mercadorias no } \\
\text { tempo e no espaço e } \\
\text { seus significados } \\
\text { históricos, levando } \\
\text { em conta o respeito } \\
\text { e a solidariedade } \\
\text { com as diferentes } \\
\text { populações. }\end{array}$ \\
\hline
\end{tabular}

Fonte: Elaborado pelos autores. 


\section{Considerações Finais}

A vivência da interdisciplinaridade ainda precisa ser incorporada por espaços de produção escolar. Portanto, a possibilidade em lançamento de propostas metodológicas, no formato de sequência didática, constitui forte estratégia de ensino para atender a dimensão integralizadora e agregadora de saberes curriculares.

Sobre esse objeto metodológico, propõe-se, neste estudo, uma sequência didática mobilizadora da construção de uma Educação Ambiental, voltada ao lugar de vivências sociais e escolares. Para isso, serão abordadas questões que envolvem o plástico, como descarte adequado, reutilização, reciclagem.

A proposta pedagógica lançada encontra-se referendada pela BNCC, documento em que consta que competência é definida como a mobilização de conhecimentos (conceitos e procedimentos), habilidades (práticas, cognitivas e socioemocionais), atitudes e valores para resolver demandas complexas da vida cotidiana, do pleno exercício da cidadania e do mundo do trabalho. O aprendizado não ocorre apenas dentro da sala de aula. A escola precisa estar aberta ao que ocorre fora dela. O ensino deve considerar como se processa a aprendizagem dos estudantes, evidenciar a importância de uma socialização e intervenção que possibilite a todos manifestar saberes com fim social.

A sequência didática interdisciplinar proposta constitui um importante recurso para os processos de ensino e de aprendizagem, pois visa articular os saberes curriculares da escola com a Educação Ambiental de uma maneira diferenciada e instigante e tem potencial para ser aplicada em diferentes contextos escolares, tendo sempre em mente que as disciplinas dialogam constantemente com as outras áreas do conhecimento, e, por meio de ações concretas, o aprendizado do aluno é favorecido.

\section{Agradecimentos}

Conselho Nacional de Desenvolvimento Científico e Tecnológico - CNPq.

\section{Referências}

Brasil Escola. (2016). Categorias da Geografia. https://brasilescola.uol.com.br/geografia/categorias-geografia.

Brasil. (2010). Conselho Nacional de Educação. Câmara de Educação Básica. Parecer nº 11 , de 7 de julho de 2010. Diretrizes Cu rriculares Nacionais para o Ensino Fundamental de 9 (nove) anos. Diário Oficial da União, Brasília, 9 de dezembro de 2010, Seção 1, p. 28. https://cutt.ly/pcaNK4x.

Brasil. (2017). Secretaria de Educação Básica. Diretoria de Apoio à Gestão Educacional Ministério da Educação. Secretaria de Educação Fundamental. Base Nacional Comum Curricular (BNCC). SEB. https://cutt.ly/vca307w.

Lei $n^{\circ}$ 9.795, de 27 de abril de 1999. Dispõe sobre a Educação Ambiental, institui a Política Nacional de Educação Ambiental e dá outras providências. http://www.planalto.gov.br/ccivil_03/leis/19795.htm.

Cunha, M. I. (2010, outubro). O campo da iniciação à docência universitária como um desafio. Anais da $33^{a}$ Reunião Nacional da ANPED, 2010. https://cutt.ly/Uca0RIX.

Ferreira, M. E. de M. P. Prólogo: perceber-se interdisciplinar. In: Fazenda, I. C. A. (org.). Práticas interdisciplinares na escola. Cortez, $2011.11-12$.

Freire, P. (1987a). Aprendendo com a própria história. (2a ed.). Paz e Terra.

Freire, P. (1995). O processo do conhecimento na Pedagogia da Libertação. Vozes.

Freire, P. (1996). Pedagogia da autonomia: saberes necessários à prática educativa. Paz e Terra.

Freire, P. (1987b). Pedagogia do oprimido. (17a ed.). Paz e Terra.

Grün, M. (1994). Uma discussão sobre valores éticos em Educação Ambiental. Revista Educação \& Realidade. 19(2), $171-195$.

Infoescola. (2005). Plásticos. https://www.infoescola.com/quimica/plasticos.

Jantsch, A. P., \& Bianchetti, L. (1995). Interdisciplinaridade: para além da filosofia do sujeito. Vozes. 202. 
Research, Society and Development, v. 10, n. 5, e15710514808, 2021

(CC BY 4.0) | ISSN 2525-3409 | DOI: http://dx.doi.org/10.33448/rsd-v10i5.14808

Lima, A. (1984). Ecologia humana. Vozes.

Lück, H. (2013). Pedagogia interdisciplinar: fundamentos teórico-metodológicos. (18a ed.). Vozes.

Medeiros, E. W. (1997). Educação e cidadania. Revista Vidya, 16(28), 55-63.

Morin, E. (2012). A cabeça bem-feita: repensar a reforma, reformar o pensamento. Bertrand Brasil.

Morin, E. (2003). Introdução ao pensamento complexo. (4a ed.). Sulina.

Morin, E. (1997). O método I: a natureza da natureza. (3a ed.). Publicações Europa - América.

Piatti, T. M., \& Ferreira, R. A. (2005). Plásticos: características, usos, produção e impactos ambientais. Universidade Federal de Alagoas.

THIOLLENT, M. (2009). Metodologia da pesquisa-ação. 17 ed. São Paulo: Cortez.

Vestena, R. F, Ortiz, A. C. M., \& dos Santos, E. A. G. (2018). RUÍNAS DE SÃO MIGUEL DAS MISSÕES/RS E FORMAÇÃO DOCENTE: a saída de campo como recurso pedagógico interdisciplinar nos anos iniciais. Itinerarius Reflectionis, 14(2), 01-23.

Yázigi, E. (2001). A alma do lugar: turismo, planejamento e cotidiano. Contexto.

ZABALA, A. (1998). Prática educativa: como ensinar. Porto Alegre: Artmed. 